\title{
Integrating Science and Policy Through Stakeholder-Engaged Scenarios
}

\author{
Emily J. Barbour, Andrew Allan, Mashfiqus Salehin, \\ John Caesar, Robert J. Nicholls, and Craig W. Hutton
}

\subsection{Introduction}

Scenarios are widely used to explore plausible future alternatives given the high degree of uncertainty in future projections (see Mahmoud et al. 2009; Rounsevell and Metzger 2010 for reviews). They can be effective in guiding planning strategies through identifying shared visions of future outcomes, as well as assessing the effectiveness of different interventions

E. J. Barbour $(\bowtie)$

School of Geography and the Environment, University of Oxford, Oxford, UK

A. Allan

School of Law, University of Dundee, Dundee, UK

M. Salehin

Institute of Water and Flood Management, Bangladesh University of Engineering and Technology, Dhaka, Bangladesh

J. Caesar

Met Office Hadley Centre for Climate Science and Services, Exeter, Devon, UK

(C) The Author(s) 2018

R. J. Nicholls et al. (eds.), Ecosystem Services for Well-Being in Deltas, https://doi.org/10.1007/978-3-319-71093-8_9 
in terms of performance against future uncertainties. Scenarios already form a key part of Bangladesh's planning process through the development of Vision 2021 and the associated Perspective Plan, which map out a desired scenario for Bangladesh in 2021 (GED 2012). Further, scenarios are a core element of the developing Bangladesh Delta Plan 2100, which provides a long-term adaptive and integrative planning framework up to 2050 and 2100 (BanDuDeltAS 2014; GED 2015).

This research adopts a scenario process which draws upon the latest global climate change community scenarios which consider climate emissions and socio-economic change (Moss et al. 2010; Kriegler et al. 2012; IPCC 2014). These global scenarios are modified to reflect local issues which are of specific relevance to stakeholders and decision makers. The project combines three climate change scenarios with three socioeconomic scenarios to cover a range of plausible futures for coastal Bangladesh. The combination of these nine scenarios was aimed at identifying a range of possible future change, as well as investigating the effectiveness of different management interventions. Most importantly, the development of these scenarios was aimed at generating a dialogue across institutions and sectors to create a shared vision of the future and address existing challenges in a holistic and integrated way.

A critical component of the scenario development process has been stakeholder involvement as part of an iterative learning loop (Fig. 9.1). As described in Chap. 4, the iterative learning loop involved co-development of qualitative and quantitative scenarios with stakeholders using an iterative process. Around 60 institutions (including government authorities, multi- and bi-lateral donors, local and international non-governmental organisations (NGOs), academic institutions and individual experts) have been involved in identifying key issues, developing baseline scenarios and identifying management interventions over a series of stakeholder

R. J. Nicholls

Faculty of Engineering and the Environment and Tyndall Centre for Climate Change Research, University of Southampton, Southampton, UK

C. W. Hutton

Geodata Institute, Geography and Environment, University of Southampton, Southampton, UK 


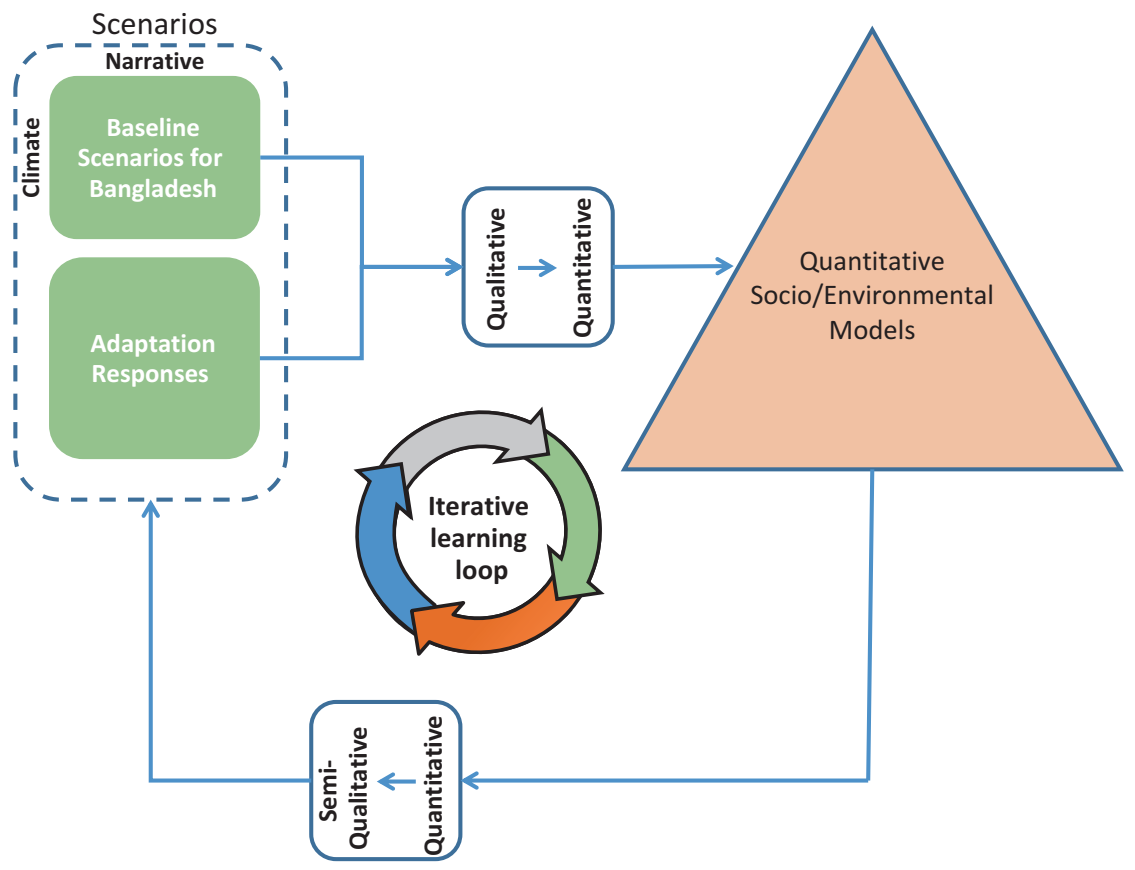

Fig. 9.1 Developing qualitative and quantitative scenarios through an iterative learning loop with project partners and stakeholders (Adapted from Nicholls et al. 2016)

workshops. This process has created three plausible future storylines considering governance, institutional change, economics, social values and the natural environment. It has enabled the quantification of these scenarios in a range of integrated detailed biophysical and socio-economic models which can be used to identify pathways out of poverty and improved well-being. Furthermore, it has facilitated the cross-institutional and cross-sectoral discussions needed to address and manage such complex systems (Holling 1978; Liu et al. 2007).

The following sections provide further details of the scenario process, beginning with an overview of the scenario framework, followed by an outline of the climate and socio-economic scenarios, and finishing with key outcomes. The results of the scenario analysis using the individual and integrated models are described in Chaps. 13, 14, 15, 16, 17, 18, 19, $20,21,22,23,24,25,26,27$, and 28 , whilst further detail regarding stakeholder engagement is provided in Chap. 10. 


\subsection{Scenario Framework}

The scenarios adopted combine three socio-economic development pathways up to 2050 and three alternative future climates up to 2099 (Table 9.1). 2050 was selected as the limit of the socio-economic projections due to both the high level of uncertainty in projecting such changes to longer time frames and to maximise consistency with local strategic planning timescales. Whilst there is also significant uncertainty in changes in climate, for known inputs the existing models allow such projections up to 2099 (and potentially longer). The climate projections represent a range of plausible changes in temperature and precipitation over the Ganges-Brahmaputra-Meghna (GBM) region, incorporating uncertainty in model parameter values. The three socio-economic development scenarios are based on the shared socio-economic pathways (SSPs) (Kriegler et al. 2012; O’Neill et al. 2012; IPCC 2014) as explained below. Each scenario was downscaled in a stakeholder-led process of discussion in workshop rather than as a quantitative exercise. The result was three locally specific socio-economic scenarios with a high level of detail, providing a distinct approach to identifying locally relevant scenarios for coastal Bangladesh.

The climate and socio-economic scenarios are summarised in Sects. 9.3 and 9.4, whilst further information on the climate analysis can be found in Chap. 11 and Caesar et al. (2015). Specific economic scenarios are described in Chap. 12.

Table 9.1 Combination of climate and socio-economic scenarios with nomenclature

\begin{tabular}{lllll}
\hline & \multicolumn{3}{l}{ Socio-economic scenario } \\
\cline { 3 - 5 } Climate scenario & $\begin{array}{l}\text { Less } \\
\text { Sustainable }\end{array}$ & $\begin{array}{l}\text { Business As } \\
\text { Usual }\end{array}$ & $\begin{array}{l}\text { More } \\
\text { Sustainable }\end{array}$ \\
\hline Q0 & $\begin{array}{c}\text { Warmer }\left(+2.2^{\circ} \mathrm{C}\right) \text { and wetter } \\
(+8 \%)\end{array}$ & Q0-LS & Q0-BAU & Q0-MS \\
Q8 & $\begin{array}{c}\text { Warmer }\left(+2.5^{\circ} \mathrm{C}\right) \text { and drier } \\
(-1 \%)\end{array}$ & Q8-LS & Q8-BAU & Q8-MS \\
Q16 & $\begin{array}{c}\text { Warmer }\left(+2.7^{\circ} \mathrm{C}\right) \text { and much } \\
\text { wetter }(+10 \%)\end{array}$ & Q16-LS & Q16-BAU & Q16-MS \\
\hline
\end{tabular}




\subsection{Climate}

A coupled global (HadCM3) (Gordon et al. 2000; Pope et al. 2000; Collins et al. 2001) and regional (HadRM3P) (Massey et al. 2015) climate model developed by the Met Office Hadley Centre was used to project temperature and precipitation across the GBM region up to 2099 (Collins et al. 2011; Caesar et al. 2015). Given uncertainty in climate model parameter values, 17 different combinations of parameter values were used to identify ranges in possible temperature and precipitation changes (see Chap. 11, Fig. 11.3). Despite substantial variability between the 17 iterations, all projections indicate a warmer and wetter climate by 2099 .

From these 17 scenarios, three were selected for application in the models to cover a range of possible change (Q0, Q8 and Q16). Ensemble members were selected to provide a central baseline (Q0), a warmer and drier scenario during the mid-century (Q8), and a much warmer and wetter scenario for both 2050 and 2099 (Q16). Sea-level rise is also a critical issue for Bangladesh. Global sea-level rise scenarios are based directly on the Fifth Assessment Report of the Intergovernmental Panel on Climate Change (Church et al. 2013). These are not explicitly coupled to the Q0, Q8 and Q16 scenarios, and their application is explained in the relevant chapter (see Chaps. 14 and 16). Land subsidence is taken from observations (Chap. 15), while example cyclones are used to illustrate their possible effects (Chap. 16).

\subsection{Socio-economic Change}

Three socio-economic scenarios were developed to cover a range of plausible patterns of future development based on locally relevant issues identified by stakeholders. A Business As Usual (BAU) scenario was used to represent stakeholder expectations of the future assuming development patterns continue as they have in the recent past and is similar to the SSP2 Middle of the Road scenario. A More Sustainable (MS) scenario was used to represent an 'improved' (but still realistic) future, drawing 
upon elements of the SSP1 (Sustainability) scenario, whilst a Less Sustainable (LS) scenario provided a less desirable outcome and combines components of the SSP3 (Fragmentation) and SSP4 (Inequality) scenarios (O'Neill et al. 2012). No objective measure of sustainability was used in the three resulting scenarios, with More and Less Sustainable being determined solely with reference to BAU-there is therefore no suggestion that the More Sustainable future would actually achieve sustainability.

Scenario development focused on adopting an interdisciplinary approach covering key elements of the biophysical environment as well as changes in livelihoods, education, economics and governance both locally and internationally. The approach adopted involved close collaboration with stakeholders and the project team with a view to developing both qualitative narratives and quantitative scenarios for the evaluation of management interventions. As such, scenario development involved four main stages: (i) identification of key issues of relevance to stakeholders, (ii) qualitative narratives for the three baseline scenarios to 2050, (iii) quantification of the narratives for baseline scenarios and (iv) identification and evaluation of management interventions (Fig. 9.2).

The four stages of scenario development were conducted as part of an iterative process with six national level stakeholder workshops held over the period from October 2013 to May 2016, as outlined in Chap. 10. Identification of key issues and downscaling of the SSPs into the three socio-economic baseline scenarios (stage 1) and the development of the qualitative narratives (stage 2) are outlined with further description in Chap. 10. Stages 3 and 4 are described in 9.4.1 and 9.4.2.

A series of interviews were held during 2012 and 2013 with relevant stakeholders, primarily at the national level, with a view to determining

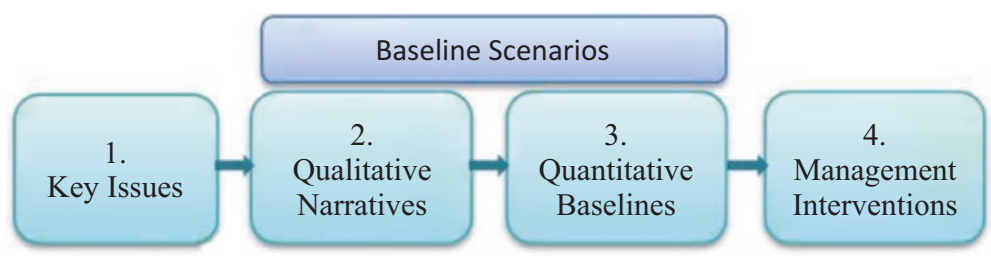

Fig. 9.2 Four stages in scenario development 
the key issues of concern in relation to longer-term livelihood and environmental protection in the south-western part of the GBM delta. This produced a list of around 15 broad issues that were broken down by stakeholders at the first workshop into 105 constituent elements, categorised into natural resource management, food security, health/livelihoods/poverty and governance. Having deconstructed each of these key issues, participants at this workshop then agreed on the extent to which each element would change by 2050 in a BAU environment, using a seven-point scale, making assumptions regarding the extent to which current trends were likely to continue or not, and taking account of existing government policy initiatives and strategic direction.

Outcomes of these interviews and workshop were used to produce a detailed and internally consistent narrative by the project team that encompassed all of the elements and their anticipated status in 2050, effectively providing a downscaled qualitative narrative for the BAU scenario. This was augmented by project members through the preparation of draft narratives describing the Less and More Sustainable scenarios, and all three narratives were closely examined by stakeholders at a subsequent workshop for plausibility and for internal and cross-scenario consistency, with further revisions made in line with stakeholder recommendations. The result was three detailed co-produced descriptions of how the socio-economic situation in Bangladesh might look in 2050, along with what stakeholders believed are the consequences on the biophysical environment (included in Chap. 10 Appendix 1). The latter consequences form the basis of the next stage, which entailed more detailed quantification.

\subsubsection{Quantification of the Qualitative Narratives}

Representation of the baseline scenarios in a modelling framework enables further investigation to understand potential changes in Bangladesh's natural resources and the dynamics between the natural environment and human well-being. The use of an integrated modelling approach can facilitate interdisciplinary discussions regarding such complex dynamics between the biophysical and socio-economic systems, to 
identify key uncertainties, and explore the effectiveness of management interventions (Voinov and Gaddis 2008). However, this requires the quantification of the qualitative narratives such that the three socioeconomic scenarios could be modelled.

This qualitative to quantitative process (referred to here as Q2Q) presents a challenge given the uncertainty in projecting changes to 2050 (and to support the biophysical modelling in some cases to 2100). As such, a five-step approach was adopted: (i) estimation of quantitative values by project members based on published data and expert knowledge where possible, (ii) identification amongst the project team of estimates which are most uncertain or unknown, and where stakeholder input would be of most value, (iii) individual stakeholder questionnaires to explore the range of responses across stakeholders and to avoid responses being influenced by dominant group members, (iv) stakeholder group discussions and consensus regarding key assumptions, and (v) iterative testing of assumptions in the modelling framework and presentation to stakeholders for feedback and modification.

Thirteen categories of model assumptions were used for consultation with stakeholders (Table 9.2). These were divided into a biophysical and socio-economic questionnaire which was emailed to participants with follow-up phone calls. Participants were primarily identified by local partners as well as through previous connections formed as part of earlier stakeholder interviews and workshops.

Following distribution of the individual questionnaires, a stakeholder workshop was held to facilitate group discussions. The workshop was attended by twenty participants from twelve external organisations and a further ten participants from partner organisations who were not directly involved in the research work. Given limited individual response to the questionnaires, the workshop began with independent completion of the questionnaires followed by sectoral group discussions, finishing with a cross-sectoral discussion.

The outcome of the Q2Q process was largely successful in terms of engaging representatives from different institutions and disciplines to discuss future changes across a range of key issues. Informal participant feedback indicated the process was interesting, useful and informative, although a number of participants found the questions challenging. 
Table 9.2 Scenario categories for quantitative biophysical and socio-economic model assumptions

\begin{tabular}{lc}
\hline Biophysical & Socio-economic \\
\hline Water resources & Migration \\
- Dam construction & - Changes in migration type \\
- Major water transfers & - Factors influencing migration \\
- Drought indices & - Influence of policy and policy \\
- Water extractions & makers \\
- Effluent discharge & Employment \\
- Sewage treatment plants & - Change in employment \\
- Deep/shallow groundwater & Literacy \\
extraction & • Change in national literacy \\
- Subsidy programmes for & - Change in rural literacy \\
groundwater & Subsidies and loans \\
- Flood management: polder height & - Current and planned subsidies \\
and maintenance & - Changes in loan provisions in \\
& rural areas \\
Land use & Poverty metrics \\
- Sundarbans encroachment & • Poverty dimensions \\
- Crop yields and salinity tolerance & - Commonly used poverty metrics \\
- Aquaculture area and technology & - Advantages/disadvantages of \\
- Change in land cover types & different metrics \\
- Land zoning programme and & \\
incentives & \\
- Access-rail/road/bridge construction & \\
Fisheries & \\
- Fishing effort & \\
- Fishing subsidies & \\
\hline
\end{tabular}

Fourteen participants completed a formal feedback form, of which the large majority indicated that the workshop had contributed to their wider understanding of ecosystem services at least to some extent, through the quantification of real conditions and assumptions, the use of narratives, assumptions and scenarios and discussion with economists about economic valuation of ecosystem services.

The process was also valuable in providing quantitative input for the modelling framework which is hoped to have improved the acceptance and validity of the modelling outputs. However, there were varying levels of response given the wide range of subjects covered by the questionnaire relative to the number of participants. Some components received much greater attention than others based on the expertise and interest within 
the groups. Time was also a limiting factor, particularly in the water resources group, where questions regarding future infrastructure development consumed most of the time with other questions on groundwater, water quality and polder management receiving little attention.

Where participants were asked to comment on values previously estimated within the project team, in general there was reasonable agreement with what had been proposed, or small suggested variations. Where participants were asked to provide new values for different assumptions, in general there was reasonable agreement between respondents in terms of overall direction and magnitude of change, but with the specific value of change varying between responses. The greatest disagreement for proposed assumptions concerned water transfer volumes and timing. Despite requesting individual responses, it was evident from some questionnaire responses that there was likely to have been discussion between participants sitting near one another. Whilst this is a limitation in not showing a full spread of individual perceptions prior to the group session, the generation of discussion about such topics is still a positive outcome.

In general, group responses reflected some elements of the individual responses, whilst in a few cases the group discussion introduced additional perspectives or changed the majority view of individuals. This change may also have been influenced by some participants joining group discussions on topics which were different from the sections they completed for the individual questionnaires. Results from the Q2Q process were disseminated to the modelling teams and incorporated into the boundary conditions for the component and integrated modelling runs.

\subsubsection{Management Interventions and Adaptation Responses}

A key strength of the adopted approach is the use of a modelling framework to allow management interventions to be tested against a range of uncertain futures, considering both climate and socio-economic change. Alongside the testing of baseline model assumptions, the main management interventions of relevance to stakeholders were also identified.

A critical element for management interventions was providing stakeholders with sufficient guidance as to what approaches could be modelled 
whilst not limiting or influencing input through leading questions. Initial efforts to have stakeholders identify interventions, irrespective of modelling capacity, were unsuccessful as stakeholders defaulted to the policies they already knew and understood. For example, stakeholder recommendations included mainstreaming poverty reduction in all development projects, proper implementation of the national social protection scheme and capacity development of local government. As these could not be analysed in the models, a series of suggestions that could be analysed were subsequently provided to stakeholders in advance of their technical discussions. These proposals included renegotiation of the Farakka Treaty, construction of the Ganges Barrage, changing polder height and other structural interventions to manage flooding and sea-level rise, improved drainage to reduce waterlogging, groundwater use policies, land zoning policies, new potential crops and subsidies for farming.

Unfortunately however, this appeared to drive group discussions and frame their proposed interventions, instead of providing indicative suggestions. It remains a challenge to have stakeholders identify interventions that are outside of existing sectoral approaches or beyond research-driven suggestions. It is for this reason that the iterative learning loop and integrated model approach (Fig. 9.1) are particularly valuable, as stakeholders have multiple opportunities to engage. After developing the inputs, they see the modelled results of their sector-driven interventions in terms of broader impacts across ecosystem services and livelihoods. They are then able to propose alternative interventions that are able to respond more directly to the integrated model results considering cross-sectoral impacts. With the application of the integrated model to test specific interventions in the Bangladesh Delta Plan 2100, this process is ongoing. The continuation of this work demonstrates the success of the approach.

\subsection{Key Insights}

Development of both qualitative and quantitative scenarios across a diverse range of biophysical and socio-economic issues facilitates crossdisciplinary discussion and learning. The scenarios present a range of plausible futures which are used to evaluate the impact of future change and the effectiveness of different management interventions. Adopting a 
systems-based approach of this scale is challenging but essential to the effective management of coastal Bangladesh and can be used to support the development of existing and future government plans including the Five-Year Plans, Vision 2021 and the Delta Plan 2100.

Involving stakeholders is critical to the success of the scenario process, as well as improving the acceptance and validity of the model and creating ownership of the process. As such, the scenario workshops are a key component of the stakeholder engagement within the research. It is intended that the scenarios are adaptive and continue to be iterated as new data and knowledge becomes available.

The scenario development processes highlighted a number of future challenges. Identifying trends in socio-economic processes with multiple interactions and dependencies is severely limited by the current capacity to understand and represent these processes, particularly in a quantitative way (Berkhout et al. 2002; Swart et al. 2004). This is further compounded by the range of scales considered, from international cooperation and macroeconomic issues through to individual and household behaviour. Despite an increasing number of studies adopting interdisciplinary scenario development down to the regional scale, the majority of these remain focused on a sub-set of future changes (e.g. flood risk-Hall et al. 2005), water resources (Soboll et al. 2011) and land use change (Baker et al. 2004; Rounsevell et al. 2005; Audsley et al. 2006), with few addressing the extent of biophysical and socio-economic changes considered in this research. In particular, there is limited evaluation of socio-economic scenarios focusing on human wellbeing and poverty (Lázár et al. 2015). This complexity creates a challenge for effective stakeholder engagement, requiring participants from multiple sectors with sufficient time to engage in the scenario process. The workshops identified that there was generally inadequate time in a single workshop to both sufficiently explain the overall context, as well as to allow stakeholders to discuss and respond to questions and invited feedback. Hence, multiple workshops and repeated engagement are critical to better engagement.

Despite these challenges, continued engagement with stakeholders throughout the scenario process is successful in developing both qualitative and quantitative plausible futures. The process has assisted in promoting dialogue about the complex dynamics influencing changes in the natural and human environment and breaking down silos between those with different expertise. 


\section{References}

Audsley, E., K.R. Pearn, C. Simota, G. Cojocaru, E. Koutsidou, M.D.A. Rounsevell, M. Trnka, and V. Alexandrov. 2006. What can scenario modelling tell us about future European scale agricultural land use, and what not? Environmental Science and Policy 9 (2): 148-162. https://doi. org/10.1016/j.envsci.2005.11.008.

Baker, J.P., D.W. Hulse, S.V. Gregory, D. White, J. Van Sickle, P.A. Berger, D. Dole, and N.H. Schumaker. 2004. Alternative futures for the Willamette River basin, Oregon. Ecological Applications 14 (2): 313-324. https://doi. org/10.1890/02-5011.

BanDuDeltAS. 2014. Inception report. Bangladesh delta plan 2100 formulation project. Dhaka: General Economics Division (GED), Planning Commission, Government of the People's Republic of Bangladesh.

Berkhout, F., J. Hertin, and A. Jordan. 2002. Socio-economic futures in climate change impact assessment: Using scenarios as 'learning machines'. Global Environmental Change-Human and Policy Dimensions 12 (2): 83-95. https:// doi.org/10.1016/s0959-3780(02)00006-7.

Caesar, J., T. Janes, A. Lindsay, and B. Bhaskaran. 2015. Temperature and precipitation projections over Bangladesh and the upstream Ganges, Brahmaputra and Meghna systems. Environmental Science-Processes and Impacts 17 (6): 1047-1056. https://doi.org/10.1039/c4em00650j.

Church, J.A., P.U. Clark, A. Cazenave, J.M. Gregory, S. Jevrejeva, A. Levermann, M.A. Merrifield, G.A. Milne, R.S. Nerem, P.D. Nunn, A.J. Payne, W.T. Pfeffer, D. Stammer, and A.S. Unnikrishnan. 2013. Sea level change. In Climate change 2013: The physical science basis. Contribution of working group I to the fifth assessment report of the intergovernmental panel on climate change, ed. T.F. Stocker, D. Qin, G.-K. Plattner, M. Tignor, S.K. Allen, J. Boschung, A. Nauels, Y. Xia, V. Bex, and P.M. Midgley. Cambridge, UK/New York: Cambridge University Press.

Collins, M., S.F.B. Tett, and C. Cooper. 2001. The internal climate variability of HadCM3, a version of the Hadley Centre coupled model without flux adjustments. Climate Dynamics 17 (1): 61-81. https://doi.org/10.1007/ s003820000094.

Collins, M., B.B.B. Booth, B. Bhaskaran, G.R. Harris, J.M. Murphy, D.M.H. Sexton, and M.J. Webb. 2011. Climate model errors, feedbacks and forcings: A comparison of perturbed physics and multi-model ensembles. Climate Dynamics 36 (9-10): 1737-1766. https://doi.org/10.1007/s00382010-0808-0. 
GED. 2012. Perspective plan of Bangladesh 2010-2021: Making vision 2021 a reality. Dhaka: General Economics Division (GED), Planning Commission, Government of the People's Republic of Bangladesh. http://www.plancomm. gov.bd/perspective-plan/. Accessed 20 July 2016.

. 2015. Seventh five year plan FY2016 - FY2020: Accelerating growth, empowering citizens. Final draft. Dhaka: General Economics Division (GED), Planning Commission, Government of the People's Republic of Bangladesh. http://plancomm.gov.bd/wp-content/uploads/2015/11/7FYP_afterNEC_11_11_2015.pdf. Accessed 6 Jan 2017.

Gordon, C., C. Cooper, C.A. Senior, H. Banks, J.M. Gregory, T.C. Johns, J.F.B. Mitchell, and R.A. Wood. 2000. The simulation of SST, sea ice extents and ocean heat transports in a version of the Hadley Centre coupled model without flux adjustments. Climate Dynamics 16 (2-3): 147-168. https://doi. org/10.1007/s003820050010.

Hall, J.W., P.B. Sayers, and R.J. Dawson. 2005. National-scale assessment of current and future flood risk in England and Wales. Natural Hazards 36 (1-2): 147-164. https://doi.org/10.1007/s11069-004-4546-7.

Holling, C.S., ed. 1978. Adaptive environmental assessment and management, ILASA international series on applied systems analysis. Chichester: Wiley.

IPCC. 2014. Climate change 2014: Impacts, adaptation, and vulnerability. Part A: Global and sectoral aspects. Contribution of working group II to the fifth assessment report of the intergovernmental panel on climate change. Cambridge/ New York: Cambridge University Press.

Kriegler, E., B.C. O’Neill, S. Hallegatte, T. Kram, R.J. Lempert, R.H. Moss, and T. Wilbanks. 2012. The need for and use of socio-economic scenarios for climate change analysis: A new approach based on shared socio-economic pathways. Global Environmental Change-Human and Policy Dimensions 22 (4): 807-822. https://doi.org/10.1016/j.gloenvcha.2012.05.005.

Lázár, A.N., D. Clarke, H. Adams, A.R. Akanda, S. Szabo, R.J. Nicholls, Z. Matthews, D. Begum, A.F.M. Saleh, M.A. Abedin, A. Payo, P.K. Streatfield, C. Hutton, M.S. Mondal, and A.Z.M. Moslehuddin. 2015. Agricultural livelihoods in coastal Bangladesh under climate and environmental change A model framework. Environmental Science-Processes and Impacts 17 (6): 1018-1031. https://doi.org/10.1039/c4em00600c.

Liu, J.G., T. Dietz, S.R. Carpenter, M. Alberti, C. Folke, E. Moran, A.N. Pell, P. Deadman, T. Kratz, J. Lubchenco, E. Ostrom, Z. Ouyang, W. Provencher, C.L. Redman, S.H. Schneider, and W.W. Taylor. 2007. Complexity of coupled human and natural systems. Science 317 (5844): 1513-1516. https:// doi.org/10.1126/science.1144004. 
Mahmoud, M., Y.Q. Liu, H. Hartmann, S. Stewart, T. Wagener, D. Semmens, R. Stewart, H. Gupta, D. Dominguez, F. Dominguez, D. Hulse, R. Letcher, B. Rashleigh, C. Smith, R. Street, J. Ticehurst, M. Twery, H. van Delden, R. Waldick, D. White, and L. Winter. 2009. A formal framework for scenario development in support of environmental decision-making. Environmental Modelling and Software 24 (7): 798-808. https://doi. org/10.1016/j.envsoft.2008.11.010.

Massey, N., R. Jones, F.E.L. Otto, T. Aina, S. Wilson, J.M. Murphy, D. Hassell, Y.H. Yamazaki, and M.R. Allen. 2015. weather@home-Development and validation of a very large ensemble modelling system for probabilistic event attribution. Quarterly Journal of the Royal Meteorological Society 141 (690): 1528-1545. https://doi.org/10.1002/qj.2455.

Moss, R.H., J.A. Edmonds, K.A. Hibbard, M.R. Manning, S.K. Rose, D.P. van Vuuren, T.R. Carter, S. Emori, M. Kainuma, T. Kram, G.A. Meehl, J.F.B. Mitchell, N. Nakicenovic, K. Riahi, S.J. Smith, R.J. Stouffer, A.M. Thomson, J.P. Weyant, and T.J. Wilbanks. 2010. The next generation of scenarios for climate change research and assessment. Nature 463 (7282): 747-756. https://doi.org/10.1038/nature08823.

Nicholls, R.J., C.W. Hutton, A.N. Lázár, A. Allan, W.N. Adger, H. Adams, J. Wolf, M. Rahman, and M. Salehin. 2016. Integrated assessment of social and environmental sustainability dynamics in the Ganges-BrahmaputraMeghna delta, Bangladesh. Estuarine, Coastal and Shelf Science 183 (Part B): 370-381. https://doi.org/10.1016/j.ecss.2016.08.017

O’Neill, B.C., T.R. Carter, K.L. Ebi, J. Edmonds, S. Hallegatte, E. KempBenedict, E. Kriegler, L.O. Mearns, R.H. Moss, K. Riahi, B. Van Ruijven, and D. Van Vuuren. 2012. Meeting report of the workshop on the nature and use of new socio-economic pathways for climate change research, November 2-4, 2011. Boulder: National Center for Atmospheric Research (NCAR). http://www2. cgd.ucar.edu/research/iconics/events/20111102. Accessed 20 July 2016.

Pope, V.D., M.L. Gallani, P.R. Rowntree, and R.A. Stratton. 2000. The impact of new physical parametrizations in the Hadley Centre climate model: HadAM3. Climate Dynamics 16 (2-3): 123-146. https://doi.org/10.1007/ s003820050009.

Rounsevell, M.D.A., and M.J. Metzger. 2010. Developing qualitative scenario storylines for environmental change assessment. Wiley Interdisciplinary Reviews-Climate Change 1 (4): 606-619. https://doi.org/10.1002/wcc.63.

Rounsevell, M.D.A., F. Ewert, I. Reginster, R. Leemans, and T.R. Carter. 2005. Future scenarios of European agricultural land use II. Projecting changes in 
cropland and grassland. Agriculture Ecosystems and Environment 107 (2-3): 117-135. https://doi.org/10.1016/j.agee.2004.12.002.

Soboll, A., M. Elbers, R. Barthel, J. Schmude, A. Ernst, and R. Ziller. 2011. Integrated regional modelling and scenario development to evaluate future water demand under global change conditions. Mitigation and Adaptation Strategies for Global Change 16 (4): 477-498. https://doi.org/10.1007/ s11027-010-9274-6.

Swart, R.J., P. Raskin, and J. Robinson. 2004. The problem of the future: Sustainability science and scenario analysis. Global Environmental ChangeHuman and Policy Dimensions 14 (2): 137-146. https://doi.org/10.1016/j. gloenvcha.2003.10.002.

Voinov, A., and E.J.B. Gaddis. 2008. Lessons for successful participatory watershed modeling: A perspective from modeling practitioners. Ecological Modelling 216 (2): 197-207. https://doi.org/10.1016/j.ecolmodel.2008.03.010.

Open Access This chapter is licensed under the terms of the Creative Commons Attribution 4.0 International License (http://creativecommons.org/licenses/ by/4.0/), which permits use, sharing, adaptation, distribution and reproduction in any medium or format, as long as you give appropriate credit to the original author(s) and the source, provide a link to the Creative Commons license and indicate if changes were made.

The images or other third party material in this chapter are included in the chapter's Creative Commons license, unless indicated otherwise in a credit line to the material. If material is not included in the chapter's Creative Commons license and your intended use is not permitted by statutory regulation or exceeds the permitted use, you will need to obtain permission directly from the copyright holder.

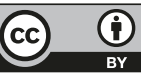

